\title{
Value Co-creation with Customer through Recursive Approach Based on Japanese Omotenashi Service
}

\author{
H. M. Belal \\ Doctoral Program (Current), Japan Advanced Institute of Science and Technology \\ 1-1 Asahidai, Nomi, Ishikawa 923-1292, Japan \\ Tel: 81-80-3280-6522Ｅ-mail: belal@jaist.ac.jp \\ Dr. Kunio Shirahada \\ Associate Professor, Japan Advanced Institute of Science and Technology \\ 1-1 Asahidai, Nomi, Ishikawa 923-1292, Japan \\ Tel: 81-761-511-747, 81-80-3727-3919 E-mail: kunios@jaist.ac.jp \\ Dr. Michitaka Kosaka (Corresponding author) \\ Dean \& professor, Japan Advanced Institute of Science and Technology \\ 1-1 Asahidai, Nomi, Ishikawa 923-1292, Japan \\ Tel: 81-761-511-745 E-mail: kosa@jaist.ac.jp
}

Received: November 28, 2012

Accepted: December 23, 2012

Online Published: January 5, 2013

doi:10.5430/ijba.v4n1p28

URL: http://dx.doi.org/10.5430/ijba.v4n1p28

The authors would like to acknowledge the Japanese Grants-in-Aid for Scientific Research (KAKENHI No.24510186) for financially supporting this research. Authors also thank our laboratory colleagues and researchers as well as business partners who gave their valuable time by sharing their knowledge and providing their valuable insights that have helped in conducting this study.

\begin{abstract}
Currently, it is a fundamental intent of a company to deliver a true solution for its users that may co-create value and indicate a servitizing company. To produce a true solution expected by a customer is very difficult, as the expected responses between customer and company usually has a gap. Therefore, this paper proposes a design method that is able to address the gaps between customers and company expectation and fill-up those gaps by gathering necessary knowledge or resources from the customer within a recursive approach concept. In addition, this study analyzes the behaviors of service providers in Japanese "Omotenashi", where the provided service gradually fit into customers' requirements according to their communication. We can apply this practice to any other organization, both in the pure service or manufacturing industry for service value co-creation. This research also discusses the application of the proposed notion to adapting servitization based on the effect of two real-life case studies.
\end{abstract}

Keywords: Recursive approach, Knowledge space, Value co-creation, Servitization, Collaboration, Customer expectations

\section{Introducation}

Today, services are a ubiquitous fraction of a firm's strategic mission and corporate planning rather than thinking as product maintenance tools. More and more corporations are shifting their vision from offering a typical product or service to total solutions aiming to translate the customers' expectations as well as esuring value co-creation. The developed economies have already started to delivere value rather than typical goods by shifting their market share from manufacturing to more product-service oriented systems (Wise and Baumgartner 1999; Neely, 2008). Therefore the reality is that the world is becoming more oriented toward services; the escalation of services is one of the key 
trends witnessed.

Service is an economic activity that creates value and provides benefits for a customer at specific times and places by bringing about a desired change in, or on be-half of, the recipient of the service (Lovelock \& Writez, 2004). Again a service is also the application of specialized competences (knowledge and skill) through deeds, processes, and performances for the benefit of another entity or the entity of itself (Vargo \& Lusch, 2004). Hence it is providing the clear message that the value is co-created through the joint attempt of firms, employees, customers, stakeholders, government agencies, and other entities related to any given exchange (Vargo et.al., 2008; Vargo \& Lusch, 2008) where the knowledge space (Belal, Shirahada \& Kosaka, 2012) is creating, that is, a source of making a required solution as well as value. The service specification for value creation usually depends on the condition (i.e. human characteristics, needs, place, time, cost and others.). In this case, the service provider needs to realize what kind of service could be perfect in which condition for the customers, but it is truly problematic to detect the perfect service for an appropriate solution that can satisfy the customer as well as co-create value with customer. The recursive approach can execute a significant role to select what kind of solution is required by users' and which service as well product is needed for producing it as this approach is able to attend to the gaps between customers and company expectation and can fill those gaps by assembling necessary knowledge or resources from the knowledge space.

Therefore, this research aims to present the analysis of a recursive approach for value co-creation by harmonizing service provider's offerings and customer's hopes based on the Japanese "omotenashi" belief. This can become a core method to make a true customer centric vision basis company. The rest of the paper is organized as follows: in Section 2, we analyze the Japanese"omotenashi"service principle as issue of service solution for co-creating value. This section also offers a model on behalf of the service value co-creation process and debates on knowledge space and recursive process in enhancing service value with customer. Section 3 designates the implementation of the Japanese "omotenashi" service for manufacturing industry that signifies as value provider. Section 4 verifies and examines the real-life case study that performs value co-creation with the customer. The final section then concludes this article with a summary.

\section{Subjects in Service Solution}

\subsection{Japanese 'Omotenashi’ Service}

The Japanese service quality, culture and background come mainly from their heart i.e. 'omotenashi'. The 'omotenashi' in Japan has very big significance that is to fullfill the guest's requirements by presenting super services from the core of the heart without expectation of any return, and the ability to actualize that idea into action. Thus, though it has a meaning similar to that of hospitality in English, it bears the image of Japanese hospitality which also suggests a deeper part of the recognition of a human being.

The Japanese hotel industry is really unique in service offerings. This sector is committed to offer exclusive and tailored service for customer, i.e. welcome greetings, dinner, hot spring, after dinner service, night service, morning service, breakfast, and Farewell greetings as well. Those kinds of service have become an important driver of market acquisition and increasing brand value for hotel industry. Here we can claim about hot spring Spa service in Japanese hotel, that it is influencing not only how consumers manage their health, appearance, and stress, but also how consumers socialize, spiritualize, travel, and work (Suna, Yoo \& Boger, 1989). To a Japanese typical high name value hotel usually belong a room clerk and concierge, who perform core character in a business development system. These two characters are providing almost the same service but they have a completely different spirit.The room clerk ensures all of services under stay until a customer arrives at a hotel and comes out of a hotel.

The crew, (who is in charge) is scheduled to prepare a midnight snack, fruit, service of breakfast, and various services such as liquidation and a send-off. From the first time of guest (customer) arrival, the room clerk usually offers the welcome greeting service, then gradually the room clerk provides all kinds of services, like: guidance to a room, preparation of dinner, tea or other items until the customer leaves a hotel. It creates the feeling of satisfaction with a customer that leads to retain a customer. Thus, the room clerk is performing a core role for gathering knowledge and improving service that considers raising the degree of satisfaction of service and to co-create value with customer.

Again, the concierge is performing another key role for conveying the outstanding service that is considered to reply a customer's question properly. In the time questioning and answering, the various knowledge and experience which a concierge has employed from a customer's viewpoint and response to which a customer is made satisfied is calculated. Therefore, in this way, a concierge becomes able to collect various kinds of information and reviews those collected information, or adds necessary information that pleases a customer and also ensures his loyalty. A 
roomclerk's and concierge's service can be described, as seen in Fig.1, as a process.

The performance of both room clerk's activities and a concierge's are like: service delivering as well as offering, and through its process are obtained significant knowledge or resources from the customer then it is added to the existing knowledge of the company, and the combined competence of knowledge (called knowledge space, Belal et.al., 2012) becomes a leading source of creating expected solution for recipents. By utilizing that source the service provider can grasp the customer's needs and feature. The customer, who feels comfortable by the type of services that is offered, and who become desires by what service points that can be distinguished slowly and then the service provider becomes able to produce as well as provide the required and suitable service for every customer. Therefore, according to time, both the service quality and performance are increasing based on user experience that is creating values for both parties.

\subsection{Service Value Co-creation Process Model}

The service offering structure and action by the room clerk and concierge (in section 2.1) was realized as a process of innovating services successively as well as raising the quality of service for harmonizing with customers' instructions.

Thus, when this process was expressed as a model, it is shown in Fig.2. Here the service provider applies its knowledge from past experience, the informer accomplishes his/her work according to the discrepancy of the customer, and has memorized as some characteristic representation customers' persona and it is decided from the reaction of the service to an actual customer whether it is applied to which persona. The determined persona, has very close characteristic with an actual customer, and has a source of service offering by which the persona may or may not satisfy. In the meantime the gap is also available between the expected reaction to the provided service and the actual reaction. Therefore, to eliminate this gap, it is essential that the service provider analyzes the rest of the gap (both external and internal), and has to enhance or innovate service or product for further offerings based on the gap analysis.

When this practice is arranged constantly by the service provider, then such gap may diminish over time and lastly it not arises. By carrying out this exercise, it becomes a service process which can co-create value with the customer and make them satisfied.

\subsection{Application of Recursive Approach for Enhancing Service Value in Japanese Omotenashi Service}

Today it is discussed that the 'value' is playing a major role in keeping customers coming back to the same service provider and the 'offering type' like; from tangible products supported with a maintenance service to total services (Boyer, Hallowell \& Roth, 2003) is performing a major role to adding value on core products. The characteristics of service and its presence in an integrated offering, employees in the providing organization and the end customers end up in a co-production relationship (Bowen \& Ford. 2002). The unit of co-production varies on the organizational effective design process and some characteristics of customer participation for example; demands, needs, expectations, behavior, experience, mindset etc. In addition it is reviled from the executive viewpoint, that when an organization forming a value proposition focused on the customer experience, then it should carefully regard on potential interactions between the components of the customer experience (Gentile \& Spiller, 2007). This study has already provided some idea in section 2.2 about recursive process that is very effective for enhancing the service value process. In this section we want to explain more preciously about the significance of recursive process for value co-creation through analyzing the provider-recipient expectation gap. In this phase, the inquiry tries to explain the recursive processes step by step as follows:

Preliminary Step; set-up persona: According to the basis of persona, the service provider typically offers services, as all customers' demands and expectations are not the same. It is dependent on the particular time, situation and characteristics as well. Therefore from the primary stage, the company (service provider) categorizes the type of persona (i.e. Persona-A, Persona-B, Persona-C or more) but it very often may not be genuine.

Secondary stage; service attribute specification: In the secondary stage, the company specifies the service line-up for offerings to customer according to corresponding with the persona type, i.e. for persona ' $A$ ' company proposes a particular set of services (welcome grating, dining and drink, opera, spa, cost etc.) and the quality of minded services also is determined from the primary period of value propositions. By the same way for persona ' $\mathrm{B}$ ', or for persona ' $\mathrm{C}$ ' or for persona ' $\mathrm{N}$ ', the service provider offer specific set of services that are already designed for specific type of persona.

Final stage; Service gap investigation and solution: In the last stage, the service provider is offering a determined set of services for customers' (i.e. service line-up-A for persona-A) but usually it is difficult to meet the real expectations 
of customers'. Thus the company detects the gap (including external and internal) by analyzing the expected response and true response. Based on the gap identification, the service provider can also become able to find the right type of persona. Hence, by realizing the type of persona and their expectations, the company tries to redesign its production, service or offerings systems as well as enhance information, skill and other necessary evidence (minimizing internal gap) aiming to meet customers' needs (reducing the external gap). Table 1 explains the recursive process according to step by step are as follows;

Hence, the recursive process is an exclusive mode that is very able to notify the necessary information continuously to the service provider according to the realization of the value and its requirement to enhance the corporation's offering until the expectation gap between the customer and the company becomes zero. So, this process is truly practical for estimating the users' (the special customer also qualifies as a user; i.e. Steve Jobs, Mike parker etc.) experiences, and is also capable to provide exact proposals of offerings according to the time demand.

\section{Omotenashi Principle in Manufacturing Industry}

\subsection{Application of Recursive Process for Value Co-creation in Manufacturing Company}

The manufacturing profitability has been declining especially in developed economies. The manufacturing firm cannot compete on the basis of cost (Neely, 2007). Van Looy, Van Dierdonck, and Gemme (2009) claimed that, nowadays, a value-creating process with a product (e.g., driving) is required by the customer, but does not require the product itself (e.g., a car). Services are competent to deliver continuous value and revenue through the life cycle of products (i.e. proactive maintenance by remote monitoring). Thus it is claimed by Vandermerwe and Rada (Vandermerwe \& Rada, 1988) that the modern corporations are increasingly offering fuller market packages or bundles of customer-focused combinations of goods, services, support, self-service, and knowledge. Additionally, it is also noted that the increasing numbers of corporations throughout the world were adding value to their core corporate offerings through services. Therefore, the clear message is the manufacturing companies' goals to shift them as 'value provider' rather than 'typical goods seller' through services on its focal product. But this value offering process successful adaptation is problematic, as the organization was well structured to offer only traditional goods, but now it desires to offer a total value package to recipients.

According to this state, the organization has realized that, for qualifying as a value source, it must stay connected with their working partners and at the same time also make a connection with the customer that becomes evidence to respond effectively and efficiently to their requirements. The uninterrupted link provides update experience over time to the service provider which is a very beneficial source for realizing, designing and delivering the expected value to the customer. The recursive approach is applicable to sustain with the global business trend as well as for gaining competitive advantages. This concept is used to control complex dynamic systems such as continuous manufacturing processes and, by applying it, the organization becomes well known concerning the appropriate service based on user experience that is required by the customer (user) as well as to co-create value.

Toyota Motor Corporation (Liker \& Morgan, 2006) is a world leading Japan-based car manufacturer with a vision focusing on the customer. This auto maker promised to deliver higher value through an innovative product (i.e. Crown, Prius) for meeting consumer demand, where Toyota is estimating user experiences recursively (both negative and positive experiences through the 'Kaizen-Hansei' principle) from the market, and its utilization is helping to realize which service or what kind of product is required by the market. Then, Toyota is managing for more vehicles launches annually through less cost with expected customer services than most of their competitors. This practice logically communicates with the customer of every Toyota project and is creating mutual understanding and value. Accordingly, Toyota becomes successful at lock-in customers and lock-out competitors which made its market capitalization greater than GM, Ford, and DCX combined, with a continuing growth in market share targeted to be 15 percent of the global market. Therefore, it is debatable that the recursive approach is very active for a traditional manufacturing company to assess customer experience and a very clear requirement of identifying the process by which a manufacturer can come to understand market demands and can produce appropriate services or products for meeting the market's as well as customers'expectations.

\subsection{Significance of Customer Experience for Interpreting Omotenashi Principle}

Customer experience is a pioneer to the customer's holistic perception of value (Lemke, Fred \& Clark, Moira \& Wilson 2003). The concept of customer experience in business or the belief of customer as decision maker was first conceived in 1980. Pine and Gilmore (Gilmore \& Pine, 1997) represent that the customer experience is a key driver of a new economic offering, which emerges as the next step after commodities, goods and services in what they call the progression of economic value. 
However, Lock-in customers and lock-out competitors through offering unique value to recipents are now a main intent of the company. For translating this vision or for meeting with the omotenashi principle, (that is promised to fullfill the guest's requirements by presenting super services from the core of the heart), some essential drivers are playing a significant role. The customer experience is one of them. Recently, many organizations have begun building in experiential content or moving to a strong experiential positioning (Gilmore \& Pine, 1997). The company is concentrating very much on customer value proposition, and for that, the assessment of customer experience is much needed. In this perspective, the company is trying to increase its relationship with recipients, which activity helps to understand as well as helps to monitor the real response of recipients. Therefore, the continuous communication is determined by the company with recipients for gathering updated experience. Such experience plays a fundamental role in determining the customers' likings, which then effect their decisions of purchasing respecting time demand.

Value is not added by goods or created by services, it is embedded in the actual experience created through active participation, as believed by Prahalad and Ramaswamy (Prahalad \& Ramaswamy. V., 2004). Karl Erik Sveiby also declared without a doubt that "competence is transferred most effectively when the recipient participates in the process". Therefore, an active contribution of consumer experiences (Karl Erik Sveiby, 1997) as well as the achievement of true experience through an endless process or by recursion could become a key responsible for value co-creation that is making a company a value provider and satisfy the customer.

\section{Value Co-creation with Customer through Recursive Approach; Verification through Real-life Case}

\subsection{Case-1; Toyota Motor Corporation (Womack et.al.,1990 \& Branco et.al., 2004)}

Purpose: To analyze the Toyota Motor Corporation's 'Hansei-Kaizen' process for problem-solving, recognizing that continuously solving root problems drives organizational learning for delivering total value to customer and create a win-win situation that is helping to touch the omotenashi concept.

Company Vision and Philosophy: To produce a reliable vehicle and sustainable development of society by employing innovative and high-quality products and services for the customer.

Company background: In 1937 (August 28), Kiichiro Toyoda founded Toyota. It is a offshoot to create automobiles from his father's company Toyota Industries. The Toyota Group is one of the largest conglomerates in the world, which is involved not only with automobile-related businesses including Toyota, Lexus, Hino and Daihatsu; but also with several "non-automotive" companies, like; Housing, Financial Activities, ITS, GAZOO, Marine, Biotechnology $\&$ Afforestation and New Business Enterprises.

However, Toyota Motor Corporation is a multinational corporation that is frequently acknowledged as Toyota. It is the world's largest automobile manufacturer by sales and targeted fifteen percent global market share. The headquarter of Toyota is located in Toyota City, Aichi prefecture, Japan.

Performance of recursive approach based on omotenashi in Toyota Motor Corporation: In 2004, the 'Toyota Way' became a hit worldwide, because it extremely explored the notion of Japanese "omotenashi" into the underlying value serving culture and thinking that manifests as the tools and techniques generally associated with lean manufacturing. However, it is Toyota's goal to ensure total value for users. With this belief, the company exceeded its expectations and was rewarded with a smile. Therefore, the company practices the 'Toyota Way', where lean services not in the manufacturing lateral but by scrutinizing Toyota's Product development system as the product (i.e. car) is the core offer for customer. Successively, how Toyota has translated the Japanese "omotenashi" to develop its product as value. In this case, Toyota become a learning as well as practicing organization over reflection (Hansei) and continuous improvement (Kaizen).

The general meaning of 'Hansei' is reflection, but it is fitting much more in Japan where it is a central idea in Japanese culture. In Japan, it is learned from childhood. Every young Japanese child knows that when he/she does something wrong: he/she is asked to engage in 'hansei' for further improvement or for nearing perfection in the future. He/she expresses deeply about his/her failing, and vows to improve and never do it again. Therefore in the 'hansei' belief, the prominence is on what was the mistake or gap, and on redesigning clear plans as well as adding more information for continuous improvement (Kaizen) to ensuring that the gap is minimized. Hence, in another word, it means to recognize the mistake or gap and to pledge improvement.

The typical Japanese meaning of 'Kaizen' is improvement, which denotes practices involving continuous improvement. Today kaizen is active in government, manufacturing, banking, engineering, healthcare service, game development, business management and others industries. It is also implemented in many other settings as well just not only productivity and business. 
However, at Toyota the main culture is 'a process for problem-solving and recognizing that continuously deliver premium solution (service or product) over reflection (Hansei) and constant improvement (Kaizen)' based on customers 'experiences. Therefore, after a project $\mathrm{s}$ isuccessfully completed, there is also a reflection meeting (Hansei-kai) to analyze where and what was missing or a gap (including external and internal). Although Toyota knows that it was a successful project, after all the company finds opportunities for improvement in the future based on the users and market experiences. This is especiall in view of value co-creation with customers.

By this continuous process, Toyota examines the gap or weakness in a project and, according to the gap analysis experience, the company takes further initiatives for filling up those lacks or minimize those gaps (via improvement services or evidence on its core offerings, e.g. a hybrid car). We can claim that this practice of Toyota is an 'appropriate solution development system' through a recursive process.

This exercise has effects on managing time, cost and quality as well as innovation of a product or service that is meeting customers' required needs and demands which typically are co-creating value. Therefore, Toyota is well accepted by the world market and has become one of the ten largest companies in the globe. Additionally, it became the largest car manufacturer in 2007 where the main code was a recursive process practice of translating the 'omotenashi' notion. The practice of recursive process for value co-creation in Toyota is shown in Fig. 4 and in Table 2 respectively;

\subsection{Case-2; Samsung Electronics Co., Ltd. (Gyewan Moon et.al., 2011)}

Purpose: Analyze continuously the customer needs and the market evolution in order to introduce novelties and become a cutting edge value provider enterprise

Company Vision and Philosophy: "Inspire the World, Create the Future." Samsung Electronics (SE) is commited to inspiring its communities and to promoting new value for Samsung's core networks Industry, Partners, and Employees.

An overview of the company: Samsung Electronics (SE) founded by Lee Bung-Chull in 1938 with the aim of world leadership and securing overwhelming competitive strength. Currently this South Korean multinational corporation is enjoying the world's largest and leading electronics and information technology company with a revenue of US\$ 119.1 billion and an operating profit of US\$ 9,920 million. The company acquired a marvelous market share in both domestic and in global markets by focusing on four business areas: Digital Media, Semiconductors, Telecommunication Networks, and LCD Digital Appliances. SE exceeded Motorola by becoming the world's second largest mobile phone maker in 2007, and became the world's largest technology company by overtaking Hewlett-Packard (HP, USA) and Siemens (Germany) by US\$125 billion in sales globally in 2009. However, still it has promissed to keep its point at the top level as a product innovative company by converging, expanding and assimilating its products, services and technologies.

Recursive approach practice based on omotenashi in SE: In 1980 SE originated the Gumi branch and it is an independent entity of SE which is known as SE Gumi. It performs an important role of business in SE. Here the main operative product is mobile phones $(80 \%)$ and fax machines $(20 \%)$. In the mobile handset perspective, the global market is currently dominated by the big six manufacturers: Nokia (37\%), Samsung (13.7\%) and Motorola (13\%) and then followed by Siemens, Sony Ericsson and LG Electronics. However, this kind of sound performance by SE Gumi is the result of optimizing their product and service inoovation continuously based on the customer requirements. According to recognizing customer experience and fulfil the customers' demands the SE Gumi followed the recursive process, where the company wants to minimize the gap between the company and customer expectations step by step.

The SE Gumi introduced the 'ProTeam' Project which is performing with $35 \%$ of their employees. This project building internal atmosphere and culture through integrates the people (employees) and their knowledge in the mobile phone manufacturing process. But it has not been enough roles to direct into innovative activities concerning the mobile phone manufacturing process that can satisfy customers. The company has tried to increase the efficiency and effectiveness of innovation of its services or products by only its internal knowledge but it is realized that there is a huge lack of innovative ideas due to the gap with market. For the offer to acquire the market as well as satisfy the customer, it is necessary to meet with customer needs, expectation and demands. Therefore, SE Gumi created an organizational mechanism called 'reinventing the wheel', where the company is able to develop new explicit or tacit knowledge through supporting knowledge sharing between the company and the user, and by utilizing 'brainstorming hours'. This redesigned knowledge is used in any type of innovative activity, not only in the new product and service design and development, but also to solve intricate troubles and suggestions by thinking about 
customers' requirements.

The customer's requirements vary in time and more specifically, it depends on the type of customer, the situation and the culture as well. From the viewpoint of the mobile phones business, it is very much driven by attractive device design and user interface configuration rather than only by advanced software and operating systems (Accenture, 2005). It stands as a big challenge for the company, since understanding customers' needs is a costly and inexact process and even when customers think they know what they want, they often cannot transfer that information to manufacturers completely (Baloh et.al., 2007). Thus SE Gumi has designed the integration of customers and suppliers into the innovation process, for example; the 'Customer decision groups and focus groups' is used for testing and feedback from Korean consumers, by which both parties (customer and company) become able to gather internal and external knowledge or experience. This experience helps the company to modify recursively any of its existing products, processes, services or frameworks according to market demands. Again, for honoring the worldwide clientele's expectations and matching with others region as well as culture, a user-friendly 'toolkit' has been developed by SE Gumi, where it suggests a Lego-style virtual external (phone housing, accessories) and a human-computer interface (software functionalities) design to a preferred costumers group (mobile phone users) from any backgrounds and any ecological locations. This is why this approach is performing as a mutual cooperative playground for provider and recipients to create a required solution as well as value that can meet any and everywhere's customers' anticipations gradually.

\section{Conclusion}

Service is a fundamental source of value creation and now its main business goal is to sustain the market by creating value. 'Omotenashi' (Japanese hospitality) symbolizes a complete value delivery ethics that is promised to satisfy guests. According to the current business viewpoint, typical manufacturers are aiming to offer a sophisticated service for adding as well as creating more value on its main product that helps to sustain the global market. The Japanese 'omotenashi' ethics is performing as a core inspiration for it but if the provider cannot simplify the true prospects of recipients then this unique ethics will not be working for value co-creation.

This research has introduced the recursive approach, which is usually very suitable as an estimator for the linear-quadratic problem (Branco \& Sanjeev, 2004) in the engineering field, but here we argued that this approach is also fits very well in the commercial business. It is very good in continuous service innovation processes through gathering customer's update experience over time and estimating the internal and external gap of the company's expected responses and customer's true responses. In the view of service value co-creation, this approach categorizes the true persona types via analyzing feedbacks of the provider and recipient, that helps to contributing right solutions to the right type of persona based on the Japanese 'omotenashi' principle. Therefore this win-win situation is building between both parties and reducing risk for the performing company by improving its competitive position in the business market.

This paper analyzed the data through the business process of the Japanese Hotel industry, Toyota Motor Corporation and Samsung Electronics Co., Ltd., where it is suggested, when an organization transforms from a product-focused to customer focused background, then it must become service-centric and be capable of responding much more actively and rapidly to the customer (Oliva \& Kallenberg, 2003). Therefore, for identifying and understanding the customers, their requirements and gathering knowledge from them is essential. In this case the recursive process is a vigorous approach for analyzing the user experience aim to minimize the gap to zero through producing or offering an expected solution for the customer that undoubtly co-creates value with the customer and means that a company is a servitized value liberator.

\section{References}

Accenture. (2005). Leadership in Customer Services: New Expectations, New Experiences. [Online] Available: http://www.accenture.com/Countries/Canada/index.htm (July14, 2006)

Baloh, P., Awazu, Y., Desouza, K. C., Wecht, C. H., Kim, J. Y., \& Jha, S. (2007, August). Roles of information technology in distributed and open innovation process. International Proceedings of the thirteenth Americas conference on information systems, Keystone, CO, USA.

Belal, H., Shirahada, K., \& Kosaka, M. (2012). Knowledge Space Concept and Its Application for Servitizing Manufacturing Industry. Journal of Service Science and Management, 5(2), 187-195.

Bowen, J., \& Ford, R.C. (2002). Managing Service Organizations: Does Having a'Thing' Make a Difference? Journal of Management, 28(3), 447-469. 
Branco, R., Sanjeev, A., \& Neil, G. (2004). Beyond the Kalman filter; Partical filter for tracking application. U.S.A: Library of Congress Cataloging-in-Publication data.

Gentile, C., \& Spiller, N. (2007). How to sustain the customer experience; An overview of experience components that co-create value with customer. European Management Journal, 25(5), 395-410.

Gilmore, J., \& Pine, II J. (1997). The four faces of mass-customization. Harvard Business Review, 75(1), 91-101.

Gyewan M., Chungshin P., Dong K., \& Choi, Y.S. (2011). Effective implimentations of communities of practices (CoPs) in knowledge habits; a case study of Samaung Electronics. International Journal of Services and Operation Management, 8(3), 335-346. http://dx.doi.org/10.1504/IJSOM.2011.038976

Lemke, F., Clark, M., \& Wilson, H. (2003). Customer experience quality: an exploration in business and consumer contexts using repertory grid technique. Journal of the Academy of Marketing Science, 39, 846-869.

Liker, J. K., \& Morgan, J. M. (2006). The Toyota Way in Services: The Case of Lean Product Development. Academy of Management Perspectives, 20(2), 5-20.

Lovelock, C., \& Writez, J. (2004). Service Marketing- People, Technology, Strategy (5 ${ }^{\text {th }}$ ed.) Upper SaddleRiver, New Jersey: Pearson Prentice Hall, (Chapter 1).

Neely, A. (2007). The Servitization of Manufacturing: An Analysis of Global Trends. Paper presented at $14^{\text {th }}$ European Operations Management Association Conference, Ankara, Turkey.

Neely, A. (2008a). Exploring the Financial Consequences of the Servitization of Manufacturing. Journal Operations Management Research, 1(2), 103-118. http://dx.doi.org/10.1007/s12063-009-0015-5

Oliva, R., \& Kallenberg, R. (2003). Managing the transition from products to services. International Journal of Service Industry Management, 14(2), 160-172.

Powar, K. S., Beltagui A., \& Riedel, J. C. K. H. (2009). The PSO Triangle: Designing Product, Service and Organization to Create Value. International Journal of Operations and Production Management, 29(5), 468-493. http://dx.doi.org/10.1108/01443570910953595

Prahalad, C.L., \& Ramaswamy, V. (2004). Co-creation experience the next practice in value creation. Journal of Interactive Marketingt, 18(13), 5-14.

Suna K.J., Jung-Eun Yoo, \& Boger Jr., C.A. (1989). Importance-performance analysis with benefit segmentation of spa goers. International Journal of Contemporary Hospitality Management, 22(5), 718-735.

Sveiby, K.E. (1997). The New Organizational Wealth; Managing and Masuring Knowledge-Based Assets. 450 Sansome Street, suit 1200, San Francisco, CA: Berrett-Koehler Publishers Inc. (Chapter 4).

Vandermerwe, S., \& Rada, J. (1988). Servitization of Business: Adding Value by Adding Services. European Management Journal, 6(4), 314-324. http://dx.doi.org/10.1016/0263-2373 (88)90033-3

Vargo, S. L., \& Lusch, R. F. (2004). Evolving to a New Dominant Logic for Marketing. Journal of Marketing, 68(1), 1-17. http://dx.doi.org/10.1509/jmkg.68.1.1.24036

Vargo, S. L., \& Lusch, R. F. (2008a). Service Dominant Logic: Continuing the Evolution. Journal of the Academy of Marketing Science, 36(1), 1-10. http://dx.doi.org/10.1007/s11747-007-0069-6

Vargo, S. L., Maglio, P. P., \& Akaka, M. A. (2008). On Value and Value Co-Creation: A Service Systems and Service Logic Perspective. European Management Journal, 26(3), 145-152.

Wise, R., \& Baumgartner, P. (1999). Go downstream: the new profit imperative in manufacturing. Harvard Business Review, 77(5), 133-141.

Womack, J.P., Jones, D.T., \& Roos, D. (1990). The machine that changed the world. New York, NY: MacMillan Press (Chapter 3).

Yaping, G. (2011). Comparative studies of Service Approach between Kyakushitsu Staff in Japanese Inn and Hotel Concierge. Unpublished Master dissertation, Japan Advanced Institute of Science of Technology, Japan. 
Table 1. Practical action stage of recursive approach

\begin{tabular}{lll}
\hline Steps & \multicolumn{1}{c}{ Activity } & \multicolumn{1}{c}{ Description } \\
\hline Step-1 & Provide service & $\begin{array}{l}\text { The company (service provider) provides a specific set of } \\
\text { services that is designed for particular persona. } \\
\text { Recognizing facts that the recipients are becoming satisfied } \\
\text { by a specific set of services or not, or what their actual } \\
\text { expectations are. } \\
\text { The service provider identifies the gap between the expected } \\
\text { response and the true response, because the customer } \\
\text { expectations and the offerings usually have some lack. }\end{array}$ \\
Step-3 & Gap identification & $\begin{array}{l}\text { After gap identification, the company becomes able to } \\
\text { recognize the true type of persona. }\end{array}$ \\
Step-5 & Gap analysis & $\begin{array}{l}\text { Currently the company knows the real type of persona and } \\
\text { their anticipations as well, so it becomes the duty of a } \\
\text { company to analyze the gap for determining which precise } \\
\text { services they must offer. } \\
\text { Allowing to the result of the 'gap study', the company } \\
\text { develops its services and offers it to the customer. }\end{array}$ \\
Step-6 & To offer expected service & $\begin{array}{l}\text { If the companies enhance their product or service } \\
\text { recursively and provide those to the customer, then once the } \\
\text { gap between the customer and the company's expectation } \\
\text { will become zero. }\end{array}$ \\
\hline
\end{tabular}

Table 2. An analysis based on practical action stage for Toyota Motor Corporation

\begin{tabular}{|c|c|c|}
\hline Steps & Activity & Description \\
\hline Step-1 & Provide service & $\begin{array}{l}\text { Toyota offers a definite Car with a set of services that is } \\
\text { thinking for a certain persona. }\end{array}$ \\
\hline Step-2 & Realize response & $\begin{array}{l}\text { Realizing data that the recipients are getting satisfied by } \\
\text { current offerings or not and collecting a true response from } \\
\text { the market and from 'Hansei-kai'. }\end{array}$ \\
\hline Step-3 & Identify the gap & $\begin{array}{l}\text { Toyota recognizes the gap between the expected response } \\
\text { and the true response based on crew data. }\end{array}$ \\
\hline Step-4 & Identify the persona & $\begin{array}{l}\text { After identifying the gap, Toyota became able to grasp the } \\
\text { exact customers' group. }\end{array}$ \\
\hline Step-5 & Analyze the gap & $\begin{array}{l}\text { By analyzing the offerings gap, Toyota develops its product } \\
\text { or service (car) on the belief of its Kaizen practice. }\end{array}$ \\
\hline Step-6 & Offer expected service & $\begin{array}{l}\text { The developed or innovative product or service (car) offers } \\
\text { to customer as well as to market as a suitable solution. }\end{array}$ \\
\hline Step-7 & The Gap become Zeros & $\begin{array}{l}\text { The users are becoming satisfied by new or enhanced } \\
\text { product or services, which is meeting customer demands. }\end{array}$ \\
\hline
\end{tabular}


Table 3. Investigation of the practice of SE based on practical action stage

\begin{tabular}{|c|c|c|}
\hline Steps & Activity & Description \\
\hline Step-1 & $\begin{array}{l}\text { Service } \\
\text { offering }\end{array}$ & $\begin{array}{l}\text { SE determines specific designed mobile phone (utilizing ProTeam's experience) with } \\
\text { precise of service for assured type of customer }\end{array}$ \\
\hline Step-2 & $\begin{array}{l}\text { Response } \\
\text { realization }\end{array}$ & $\begin{array}{l}\text { The views of market (including domestic and global market) are realizing current } \\
\text { offerings. }\end{array}$ \\
\hline Step-3 & $\begin{array}{l}\text { Find the } \\
\text { gap }\end{array}$ & $\begin{array}{l}\text { SE Gumi identifies expected feedback and true feedback based on market data (using the } \\
\text { mechanism of 'reinventing the wheel, Costumer decision groups and focus groups, } \\
\text { toolkit etc.) }\end{array}$ \\
\hline Step-4 & $\begin{array}{l}\text { Identify the } \\
\text { market } \\
\text { (persona) }\end{array}$ & $\begin{array}{l}\text { After identifying the gap of feedback the SE Gumi usually holds about market and its } \\
\text { requirments. }\end{array}$ \\
\hline Step-5 & $\begin{array}{l}\text { Gap } \\
\text { analysis } \\
\text { and idea } \\
\text { generation }\end{array}$ & $\begin{array}{l}\text { By examining the gap of product/service offering, the company improves its offering } \\
\text { invention (mobilr phone) on the belief of 'omotenashi'. }\end{array}$ \\
\hline Step-6 & $\begin{array}{l}\text { Deliver } \\
\text { predictable } \\
\text { service }\end{array}$ & $\begin{array}{l}\text { The innovative as well as developed product or service (mobile phone) offers to market } \\
\text { as proper resolution. }\end{array}$ \\
\hline Step-7 & $\begin{array}{l}\text { Minimizing } \\
\text { gap }\end{array}$ & $\begin{array}{l}\text { After getting a solution from the company, the customer becomes satisfied and also } \\
\text { performs as a loyal customer. }\end{array}$ \\
\hline
\end{tabular}

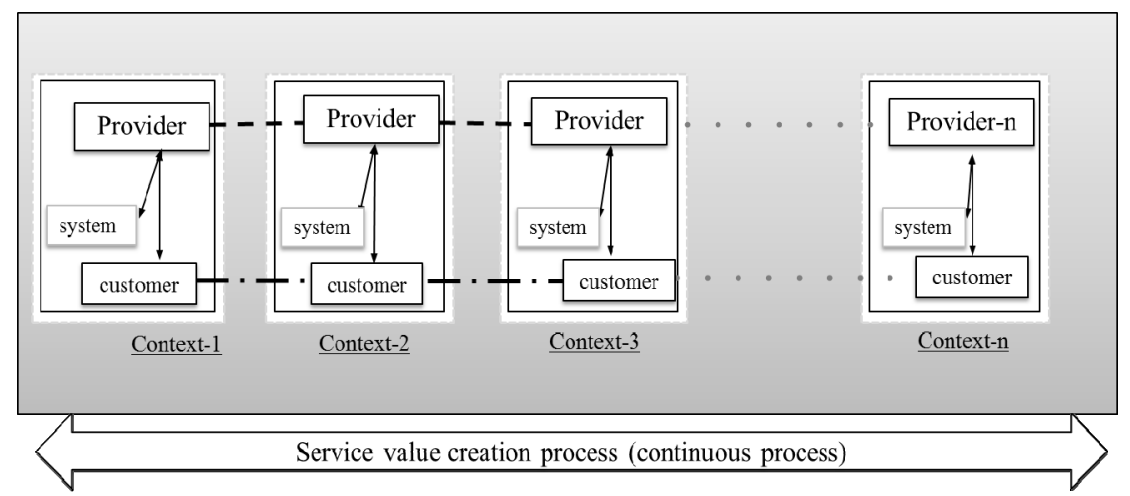

Figure 1. Service value co-creation process in hotel industry centered on Japanese omotenashi (Yaping Gao, 2011)

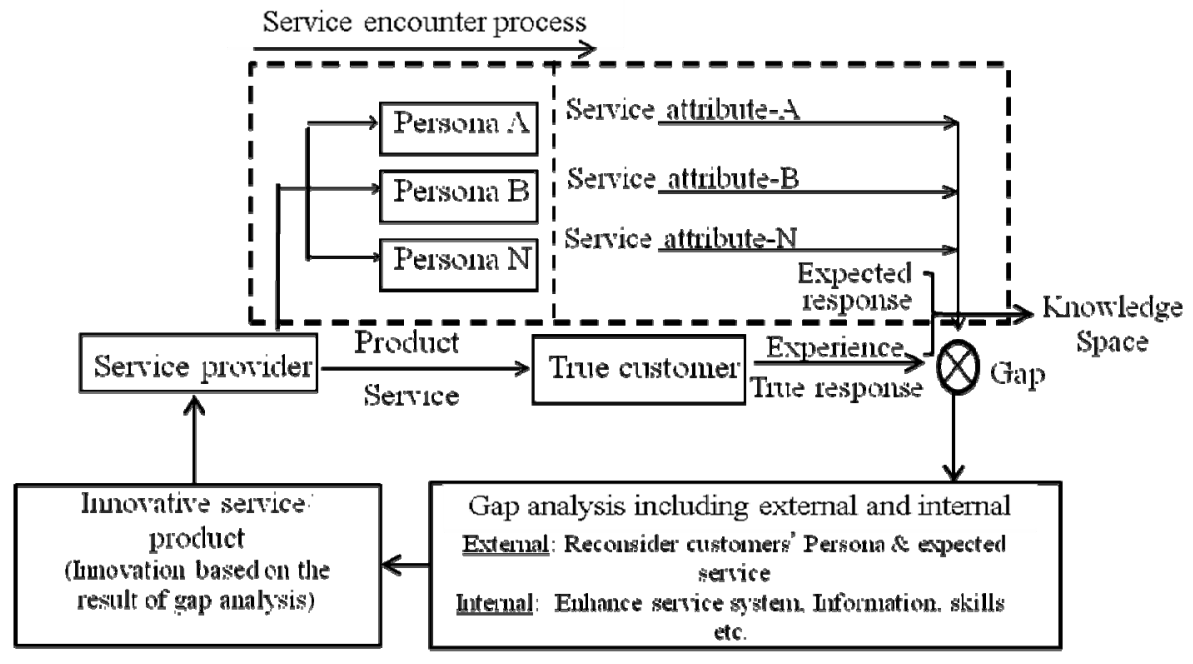

Figure 2. A recursive model for service value co-creation process 


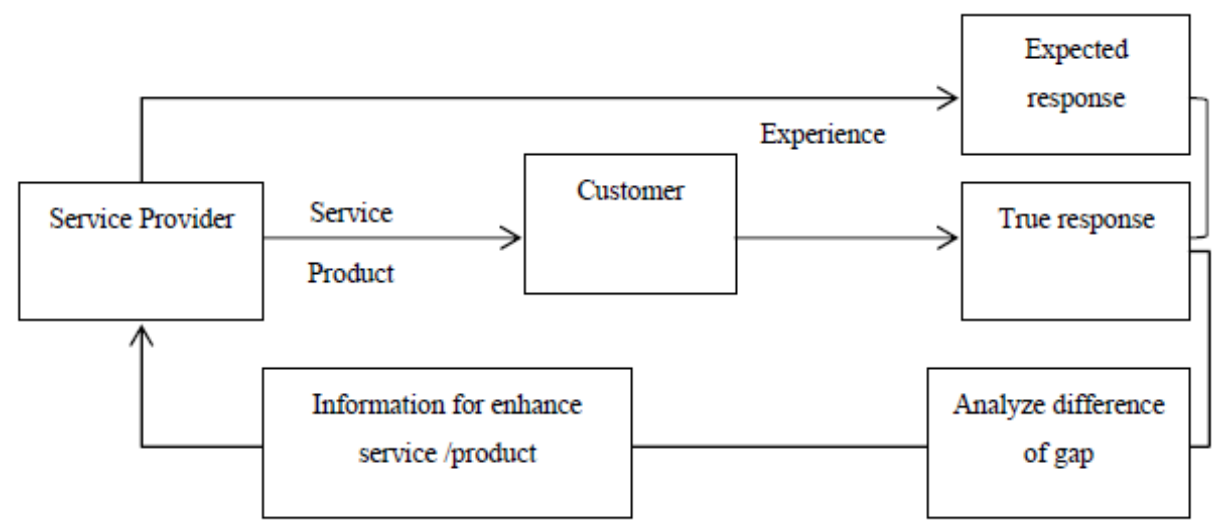

Figure 3. User's experience in the value co-creation process

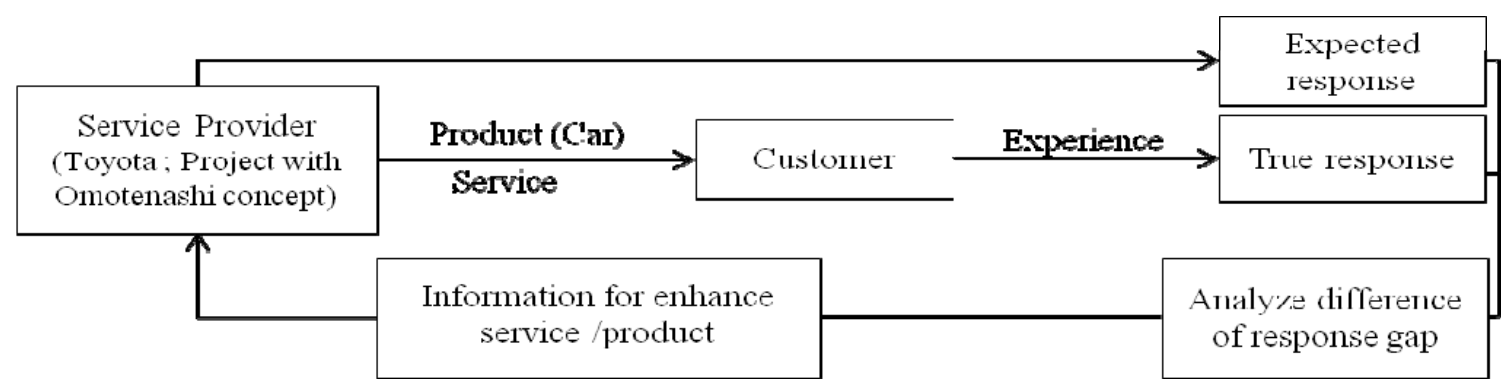

Figure 4. Value co-creation process of Toyota with customer through 'Hansei and Kaizen' practice

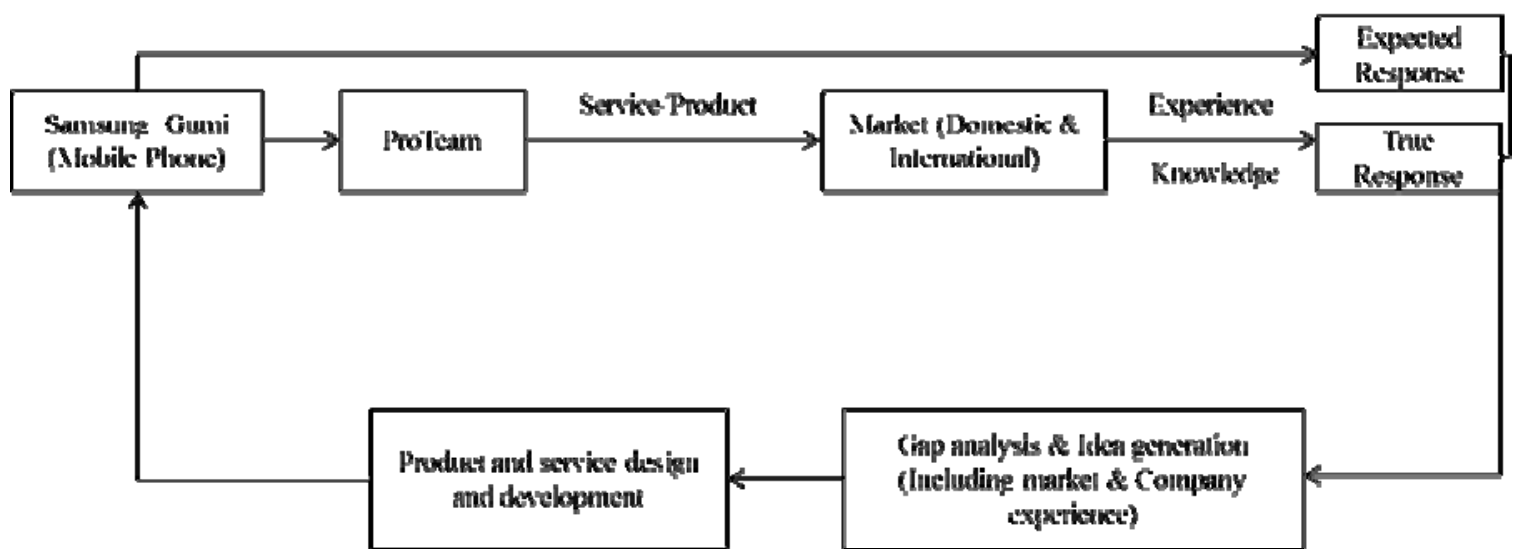

Figure 5. Recursive approach exercise in Samsung Electronic 